\title{
Experimental analysis of composite steel-concrete slabs
}

\author{
R. Karásek, J. Holomek, M. Bajer \& J. Barnat \\ Department of Steel and Timber Structures, \\ Brno University of Technology, Czech Republic
}

\begin{abstract}
Composite structures fabricated from thin-walled steel sheeting and concrete slabs are especially suitable for roof and floor bearing structures. Using embossments for the shear connection between the sheeting and the concrete simplifies and accelerates the construction process because it ensures the composite action of the two materials without any need for additional reinforcement. This article is focused on this type of connection. It contains a short review of thin-walled sheeting manufactured in Western Europe and presents results obtained from the experimental testing of specimens. These specimens were tested by vacuum loading and by cyclic loading in four-point bending tests. Small scale specimen tests were performed to determine the shear behaviour and to adjust numerical models.

Keywords: composite action, cold-formed steel sheet, concrete slab, shear connection, embossment.
\end{abstract}

\section{Introduction}

In order to ensure composite action in steel-concrete slabs, connection members must be used. Cold-formed embossments may be an effective and easily producible solution for this problem. Manufacturers in Europe offer several types of thin-walled sheeting with embossments: self-locking with dimples on the upper flange (SHR 51, Cofrastra 40) - fig. 1(a); self-locking with dimples on the slanted sides (Cofrastra 70) - fig. 1(b); trapezoidal with dimples on the upper flange (Cofraplus 220) - fig. 1(c); trapezoidal with dimples on the slanted sides (Cofraplus 60, Hi-Bond A55, Hi-Bond A75, Haircol 55S, Haircol 80S, Prins 


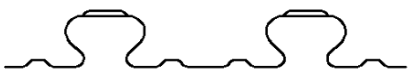

(a)

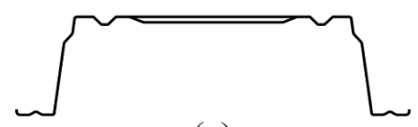

(c)

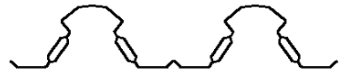

(b)

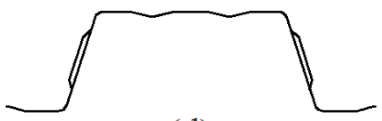

(d)

Figure 1: Examples of thin-walled steel sheeting with embossments available on the European market [7].

PSV 73) - fig. 1(d); trapezoidal with dimples on both the upper flange and the slanted sides (Inco 70.4), etc. [1].

\section{Current design methods}

Eurocode 1994-1-1 describes two methods of designing composite slabs: the $m-k$ method and the partial connection method. Both of them use several sets of fourpoint bending tests [2].

Three possible critical cross sections (fig. 2) are related to three possible failure modes (fig. 3) which can occur in composite slabs of this type. Bending failure occurs for large shear spans, vertical shear failure occurs for the shortest shear spans, and for shear spans in between longitudinal shear failure occurs.

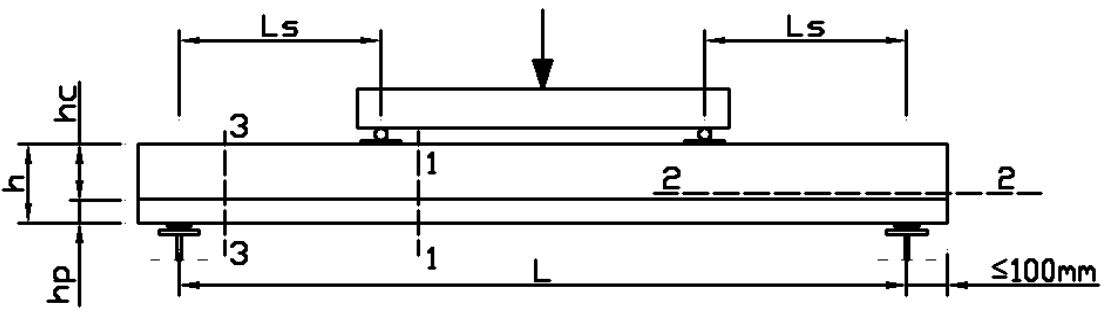

Figure 2: $\quad$ Critical cross sections in composite slabs: 1-1 for bending moment, 2-2 for longitudinal shear and 3-3 for vertical shear [1].

The necessity of the laboratory testing of whole slabs makes the described methods expensive and time consuming. Therefore, an effort is being made to create a design method in which laboratory testing is unnecessary, or less expensive, small-scale tests are used. The mutual slip between a thin-walled steel sheet and a concrete slab may be affected by many factors. Failure can occur via the local buckling of the steel sheet, the deformation of the dimples, the peeling off of concrete, the crumbling of concrete, etc. It is therefore complicated to describe the shear behaviour in a general manner [3]. 


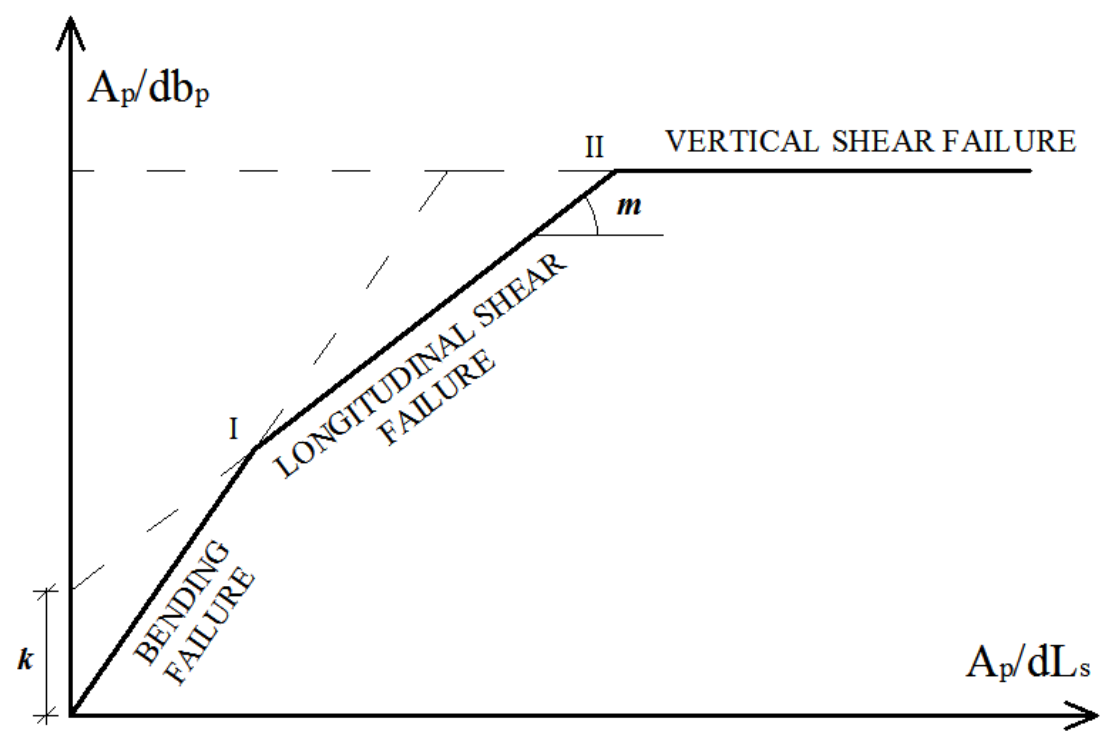

Figure 3: $\quad$ Failure modes in composite slab behaviour [1].

Data regarding load-slip dependence can be obtained from small-scale shear tests. The test setup can be different, but is usually similar to that used by Daniels or Stark (fig. 4). The difference is in the lateral constraint used: Daniels' set-up is laterally constrained, while Stark's is unconstrained [4].

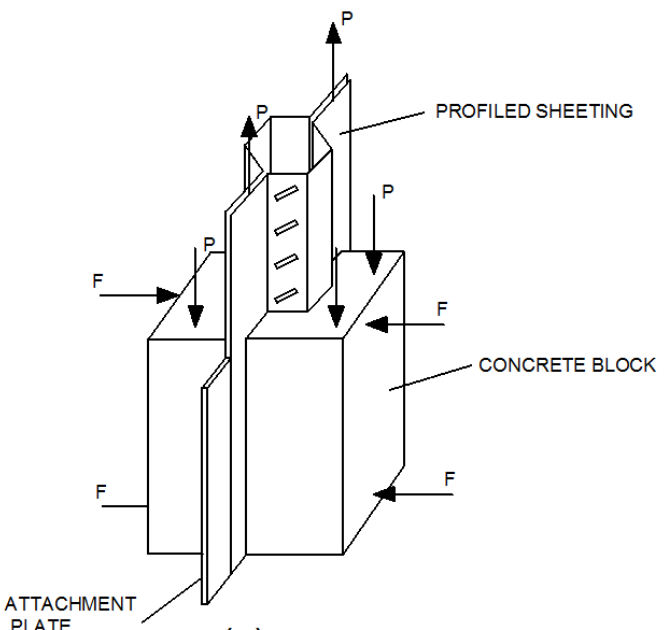

(a)

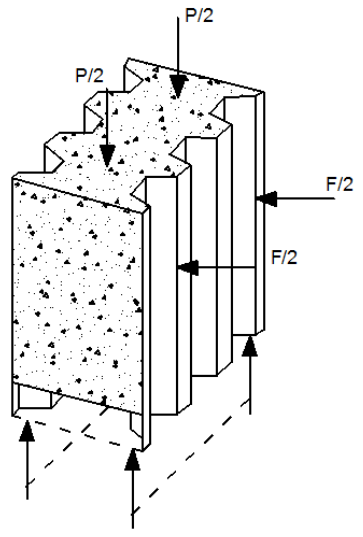

(b)

Figure 4: $\quad$ Small-scale test setups, after (a) Daniels and (b) Stark [4]. 
There are also other influences which small-scale tests cannot take into account, such as curvature due to bending, for example. For these reasons smallscale tests cannot simply totally replace the testing of whole spans.

\section{Laboratory testing}

Three different types of test were conducted in order to gain information about the real behaviour of composite slabs with embossments. These were vacuum tests, four-point bending and small-scale tests. Cofraplus 60 steel sheeting was used in the tests.

\subsection{Vacuum testing}

Vacuum technology produces an ideally uniform area load. Two series of tests were carried out on specimens with thicknesses of $110 \mathrm{~mm}$ and $150 \mathrm{~mm}$. The specimens were cast without inner supports. A photograph of the test set up with a deflection measuring device can be seen in figure 5. The imposed load was raised to $50 \mathrm{kN} / \mathrm{m}$ using a common plastic foil [5]. The load deflection dependence can be seen in figure 6 .

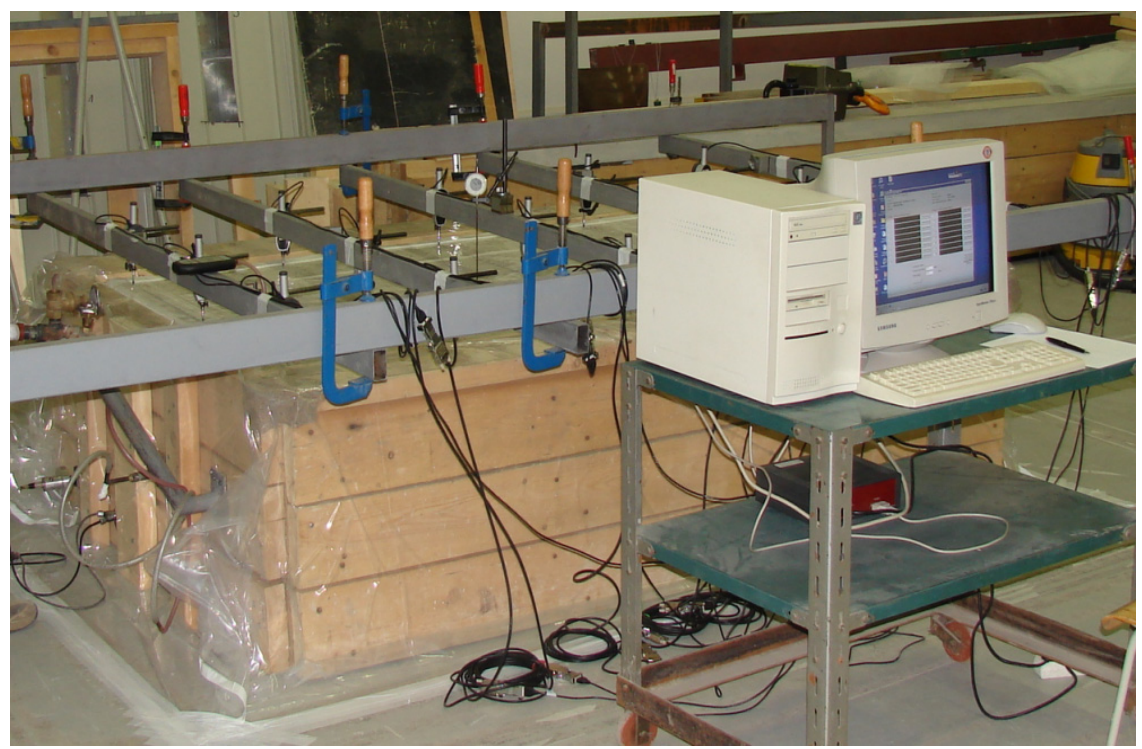

Figure 5:

Test setup for vacuum loading. 


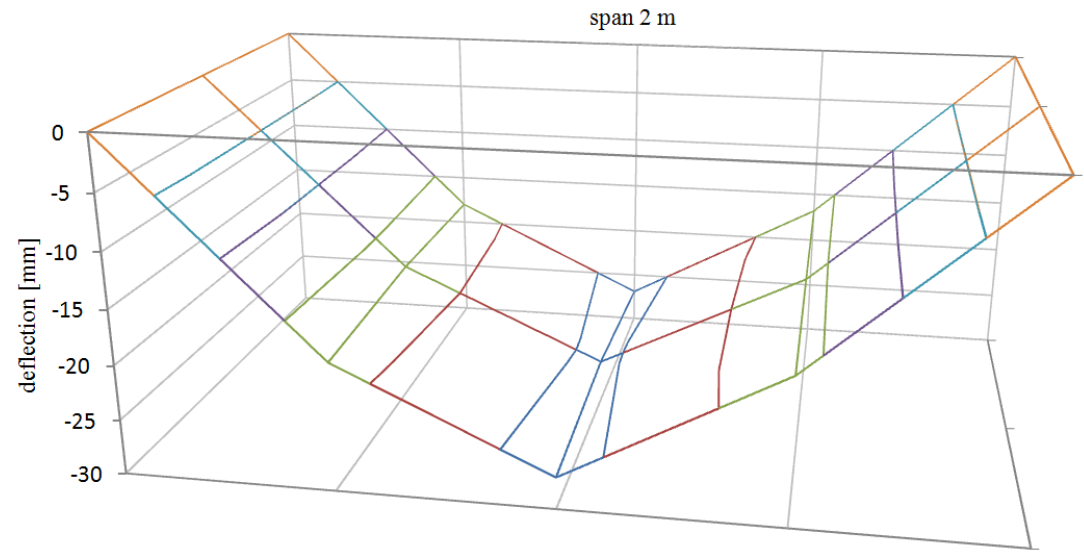

Figure 6: $\quad$ Deflection of the slab for a vacuum load of $41.18 \mathrm{kN} / \mathrm{m}$.

\subsection{Four-point bending}

The specimens were loaded by cycling load according to the test procedure described in EN 1991-1-1, Annex B (the same arrangement as in fig. 2). At first, three of the specimens were loaded statically to determine the magnitude of cycling load. Another six specimens were loaded for 5000 cycles and then statically until total destruction occurred.

In the load-slip diagram of the static test without cycling the slip is almost negligible for lower values of load. A significant increase in slip occurs at a certain value of load and then the load-slip curve grows up to total collapse (fig. 7).

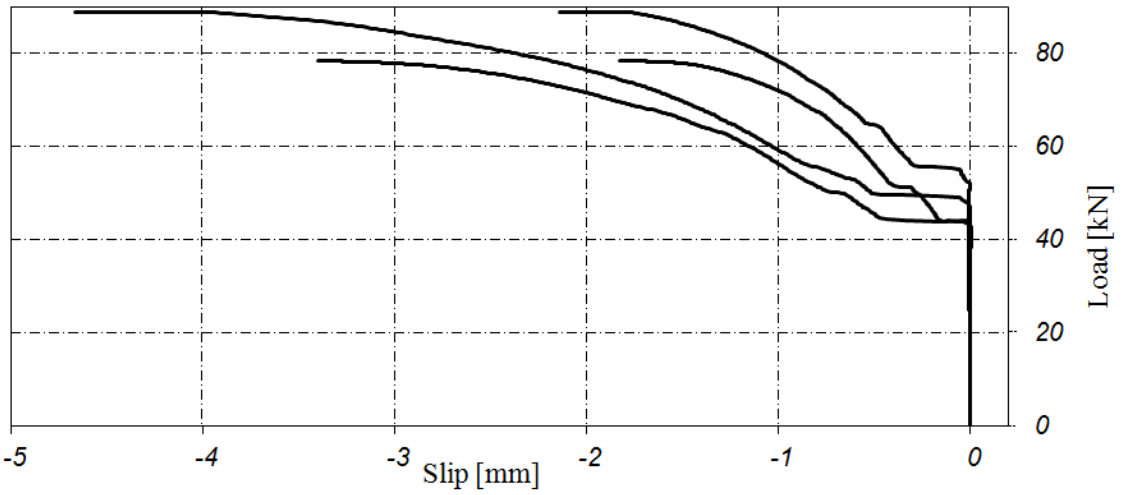

Figure 7: $\quad$ Load-slip diagram - static test without cycling. 
On the other hand, the load-slip curve of the static test after cycling grows more uniformly from lower values of load because the chemical bond between steel sheet and concrete slab has been destroyed (fig. 8) [6].

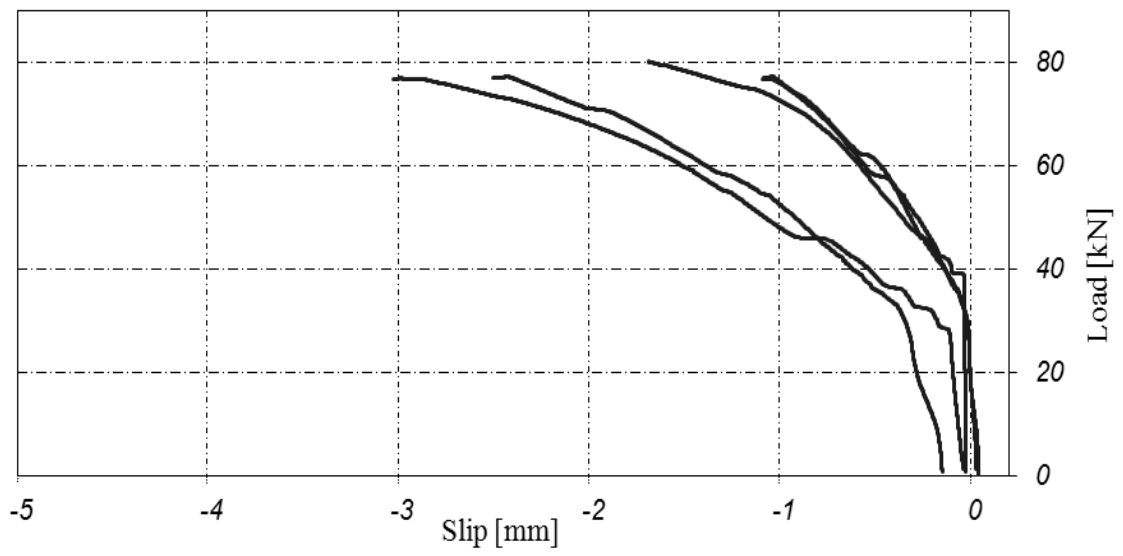

Figure 8: $\quad$ Load-slip diagram - static test after cycling.

\subsection{Small-scale test}

The test setup is displayed in figures 9 and 10. The specimens were fixed to a thick steel plate with the aid of screws driven through their steel sheets. Shear load P was applied on a vertical surface of the concrete causing the concrete part to be pushed across the steel sheet.

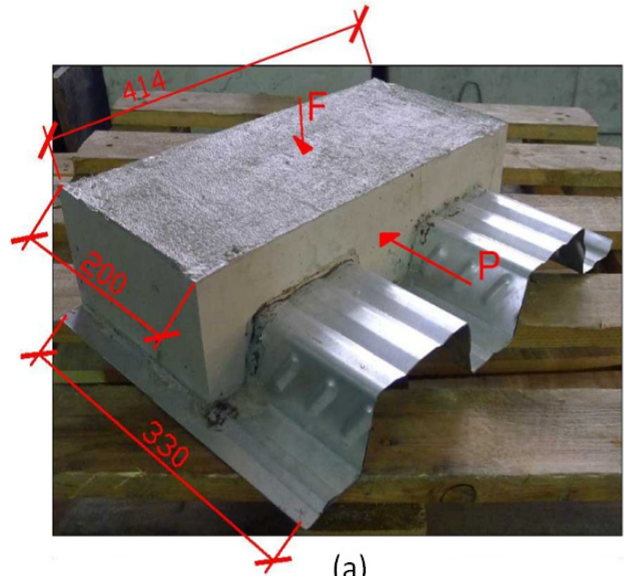

(a)

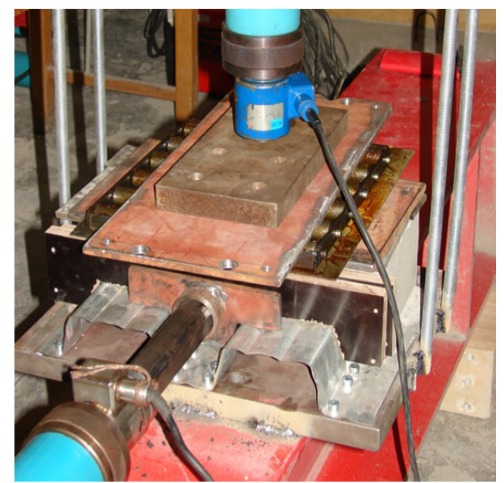

(b)

Figure 9: $\quad$ Small-scale test set-up. 


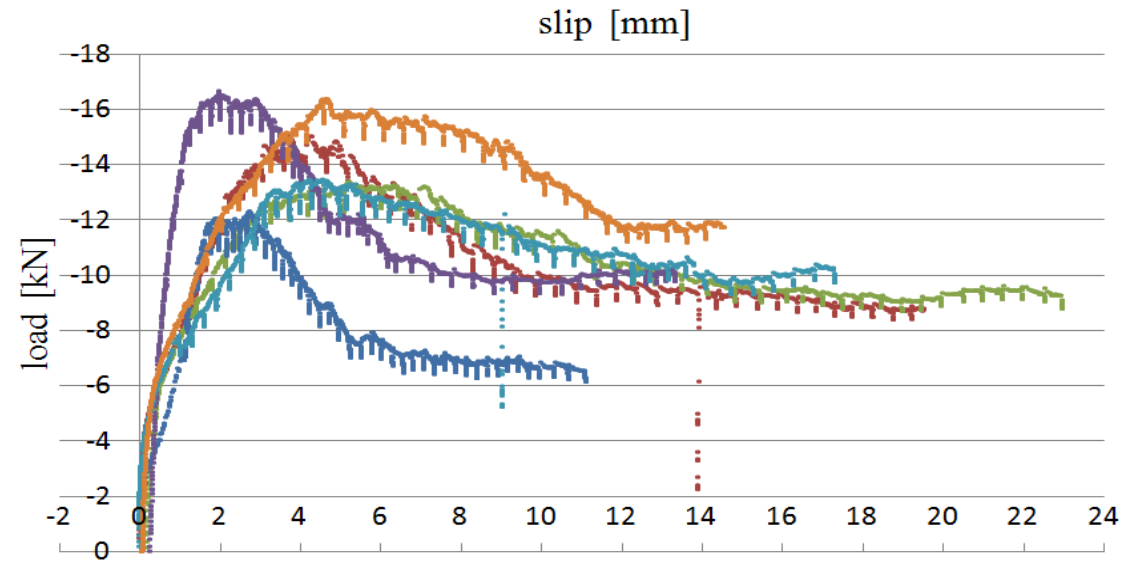

Figure 10: Load-slip diagram of small-scale specimens for a vertical load of $3.9 \mathrm{kN}$.

A vertical load, F, was applied on the top surface of the concrete, simulating a uniform load on a slab when acting on a whole span. Figure 11 shows the loadslip curve of the specimens with a vertical load of $3.9 \mathrm{kN}$. The obtained dependences from the performed initial experiments will be used to adjust numerical models and to improve the configuration of experiments where the dependence of vertical load on shear resistance can be observed.

\section{Conclusion}

A substantial disadvantage of steel-concrete slabs combined with thin-walled steel sheeting with embossments is the necessity of laboratory testing when designing steel sheeting with a new shape. One possible way of discovering a cheaper and faster design method is by using small-scale tests. The configuration of such tests cannot include all the factors which act in a real construction, but they can usefully approximate the shear properties. The several different types of tests performed in our laboratory provided information about the real behaviour of this kind of slab. The data will be used to adjust numerical models and combined with further experiments to obtain other dependences.

\section{Acknowledgements}

These results were achieved with the financial assistance of projects GACzR 103/09/H085, GACzR P104/11/P737 and BD12101030 FAST-J-13/1237. 


\section{References}

[1] Kozák, J., Gramblička, Š., Lapos, J., Spriahnuté a kombinované ocel'obetonové konštrukcie pozemných stavieb, Jaga group v.o.s., Bratislava 2000, ISBN 80-88905-32-X.

[2] EN 1994-1-1; 2004, Eurocode 4 - Design of composite steel and concrete structures - Part 1.1: General rules and rules for buildings.

[3] Ferrer, M., Marimon, F., Crisinel, M., Designing cold-formed steel sheets for composite slabs: An experimentally validated FEM approach to slip failure mechanics, Thin-Walled Structures, Volume 44, Issue 12, ELSEVIER. 2001. p.1261 - 1271. ISSN: 0263-8231.

[4] Burnet, M.J., Oehlers, D.J., Rib shear connectors in composite profiled slabs, Journal of Constructional Steel Research, Volume 57, Issue 12, ELSEVIER. 2001. p.1267-1287. ISSN: 0143-974X.

[5] Melcher, J., Full-Scale Testing of Steel and Timber Structures: Examples and Experience, In Structural Assessment - The Role of Large and Full Scale Testing, edited by K.S. Virdi et al., London: E\&FN SPON, 1997, pp.301 - 308, ISBN 0419224904.

[6] Holomek J., Karásek, R., Bajer, M., Barnat. J., Thin-walled steel sheets with indentations in composite steel-concrete structure under different types of loading, International Conference on Energy, Environment, Economics, Devices, Systems, Communications, Computers, IAASAT Press, Iasi 2011, ISBN: 978-1-61804-014-5.

[7] http://www.arcelormittal.com/distributionsolutions/construction/arval/ 